Article

\title{
Shear Response of Recycled Aggregates Concrete Deep Beams Containing Steel Fibers and Web Openings
}

\author{
Nancy Kachouh, Tamer El-Maaddawy *(D), Hilal El-Hassan (D) and Bilal El-Ariss (D) \\ Department of Civil and Environmental Engineering, College of Engineering, Al Ain Campus, United Arab \\ Emirates University, Al Ain 15551, United Arab Emirates; nancy.kachouh@uaeu.ac.ae (N.K.); \\ helhassan@uaeu.ac.ae (H.E.-H.); bilal.elariss@uaeu.ac.ae (B.E.-A.) \\ * Correspondence: tamer.maaddawy@uaeu.ac.ae
}

Citation: Kachouh, N.; El-Maaddawy, T.; El-Hassan, H.; El-Ariss, B. Shear Response of Recycled Aggregates Concrete Deep Beams Containing Steel Fibers and Web Openings. Sustainability 2022, 14, 945. https: / / doi.org/10.3390/su14020945

Academic Editor: Constantin Chalioris

Received: 2 December 2021

Accepted: 10 January 2022

Published: 14 January 2022

Publisher's Note: MDPI stays neutral with regard to jurisdictional claims in published maps and institutional affiliations.

Copyright: () 2022 by the authors. Licensee MDPI, Basel, Switzerland. This article is an open access article distributed under the terms and conditions of the Creative Commons Attribution (CC BY) license (https:// creativecommons.org/licenses/by/ $4.0 /)$.

\begin{abstract}
Replacement of natural aggregates (NAs) with recycled concrete aggregates (RCAs) in complex reinforced concrete $(\mathrm{RC})$ structural elements, such as deep beams with openings, supports environmental sustainability in the construction industry. This research investigates the shear response of RC deep beams with openings made with 100\% RCAs. It also examines the effectiveness of using steel fibers as a replacement to the minimum conventional steel stirrups in RCA-based deep beams with web openings. A total of seven RC deep beams with a shear span-to-depth ratio $(a / h)$ of 0.8 were constructed and tested. A circular opening with an opening height-to-depth ratio $\left(h_{0} / h\right)$ of 0.3 was placed in the middle of each shear span. Test parameters included the type of the coarse aggregate (NAs and RCAs), steel fiber volume fraction $\left(v_{f}=1,2\right.$, and $3 \%$ ), and presence of the minimum conventional steel stirrups. The deep beam specimens with web openings made with $100 \%$ RCAs exhibited 13 to $18 \%$ reductions in the shear capacity relative to those of their counterparts made with NAs. The inclusion of conventional steel stirrups in RC deep beams with openings was less effective in improving the shear response when 100\% RCAs was used. The addition of steel fibers remarkably improved the shear response of the tested RCA-based beams. The gain in the shear capacity of the RCA-based beams caused by the inclusion of steel fibers was in the range of 39 to $84 \%$, whereas the use of conventional steel stirrups resulted in $18 \%$ strength gain. The use of $1 \%$ steel fiber volume fraction in the RCA-based beam with openings without steel stirrups was sufficient to restore $96 \%$ of the original shear capacity of the NA-based beam with conventional steel stirrups. The shear capacities obtained from the tests were compared with predictions of published analytical models. The predicted-to-measured shear capacity was in the range of 0.71 to 1.49 .
\end{abstract}

Keywords: recycled concrete aggregates; steel fibers; shear behavior; deep beams; web openings

\section{Introduction}

At the end of their service lives, aged concrete structures are demolished creating massive amounts of construction and demolition waste (CDW). This CDW is mostly disposed of in stockpiles or landfills, causing serious environmental hazards [1]. A sustainable solution to the problem of CDW and the scarcity of natural resources for natural aggregates (NAs) is the concept of recycling this waste in the form of recycled concrete aggregates (RCAs). The potential substitute of NAs by RCAs is considered a promising approach to promote the use of sustainable materials in construction. The use of RCAs in concrete mixtures has been accompanied by a decrease in its mechanical performance compared to its conventional counterpart [2-4]. Nevertheless, its positive environmental impact has driven researchers to investigate the effect of its usage in structural applications such as reinforced concrete (RC) beams. The shear behavior of RC beams with RCAs is an important aspect that requires investigation and experimental evidence prior to using RCAs routinely in structural applications [5-9].

Reinforced concrete deep beams are important structural members generally used as load-transferring elements, such as transfer girders in high rise buildings, pile caps, tanks, 
folded plates, and foundation walls. A deep beam is defined by the ACI 318-14 [10] as a structural element in which either the clear span is equal to or less than four times the overall depth, or the concentrated loads are applied within a distance equal to or less than two times the depth from the face of the support. A few studies were conducted on RC deep beams made with RCAs [6-8]. Outcomes of some studies indicated that full replacement of NAs by RCAs in concrete deep beams reduced the shear capacity and stiffness [6]. In contrast, other studies reported that the shear behavior of NA- and RCA-based concrete deep beams was comparable [8].

The inclusion of web openings in RC deep beams is frequently required to provide passage for electrical and mechanical ducts [11-15]. Web openings produce discontinuity in the normal flow of stresses which reduces the beam shear capacity and stiffness [11-15]. The reduction in shear capacity is more significant when the opening fully interrupts the natural load path [11-15]. The impact of varying the concrete compressive strength on the shear capacity of RC deep beams significantly decreased in the presence of web openings [12]. Inclined web reinforcement was the most effective type of reinforcement for controlling diagonal crack width and increasing the load capacity [13]. Higher shear capacity can be achieved through the use of web reinforcement above and below the opening rather than proving reinforcement above the opening only [13]. Horizontal stirrups distributed along the beam depth were found to be more efficient than vertical stirrups for RC deep beams with an opening in the shear span [14]. Very few studies have covered the topic of RC deep beams made with RCAs and web openings [16]. The use of RCA replacement percentage less than $75 \%$ in concrete deep beams with a shear span-to-depth ratio $(a / h)<2$, opening height-to-depth ratio $\left(h_{0} / h\right)$ of 0.3 , and web reinforcement above and below the opening did not result in a reduction in the shear capacity [16].

To counteract the strength reduction when RCAs are used in concrete, different solutions were proposed [17]. The addition of steel fibers to a concrete matrix has been found to reduce the development of microcracks and improve different tensile properties of concrete [18-20]. Previous studies indicated that steel fibers can be used in RC beams as a substitution to the minimum steel stirrups which can potentially reduce the congestion of reinforcing bars and operational costs [21-30]. The use of steel fibers delayed the formation and widening of cracks and improved the shear cracking and ultimate loads of RC deep beams with openings [26-29]. The improvement in shear capacity became higher with increasing the content of steel fibers and decreasing $a / h$ [29]. Similarly, deep beams with web openings became stiffer with an increase in the steel fiber content [29]. Steel fiber-reinforced concrete deep beams, with an $a / h$ of $1, v_{f}$ of $1.5 \%$, and $h_{0} / h$ of 0.3 , reached higher strength than the design load of a similar beam without fibers having conventional steel reinforcing bars above and below the opening [30]. The use of steel fibers also improved the post-peak response of the tested beams [30].

There is a lack of knowledge on the shear response of RC deep beams made with 100\% RCAs having steel fibers and web openings. The effectiveness of using steel fibers as a replacement to conventional steel stirrups in RC deep beams with web openings made with $100 \%$ RCAs has not been investigated previously. This research aims at filling this gap through experimental testing and comparative analysis with predictions of published analytical models.

\section{Research Significance}

Utilizing recycled materials reduces the demand for natural resources and promotes environmental sustainability in the construction industry. Steel fibers have a potential to improve properties of recycled aggregates concrete and replace conventional steel stirrups in RCA deep beams with openings, thus eliminating congestion of steel reinforcing bars around the opening, and reducing the risk of occurrence of honeycombs and defects. This research provides new knowledge on the shear response of RC deep beams with web openings made with $100 \%$ RCAs. The shear behavior of RCA deep beams with and without conventional steel stirrups is compared to that of similar beams made with NAs. The 
effectiveness of using steel fibers as a replacement to conventional steel stirrups in RCA deep beams with openings is elucidated. The widespread use of RCA-based concrete in structural application would lead to more sustainable buildings and promote the concept of circular economy.

\section{Experimental Program}

The experimental program is composed of testing of seven RC deep beams having $a / h$ of 0.8 having a circular web opening in each shear span. The following subsections provide details of the experimental program adopted in the current study.

\subsection{Materials}

The concrete matrix (mixture) was prepared using ASTM Type I ordinary Portland cement (OPC), desert dune sand as a sustainable fine aggregate, coarse aggregates (either NAs or RCAs), and tap water. The NAs were crushed dolomitic limestone with a nominal maximum particle size (NMS) of $19 \mathrm{~mm}$, whereas the RCAs were obtained from a concrete recycling plant that crushes CDW from old concrete structures with an unknown compressive strength to form RCAs with an NMS of $25 \mathrm{~mm}$. It is worth mentioning that the plant did not perform any chemical treatment to the obtained RCAs. The particle size distribution of the fine and coarse aggregates used in this study are shown in Figure 1a. All grading curves were within the upper and lower limit bounds specified by ASTM C33 [31]. Physical properties of the fine and coarse aggregates are published elsewhere [25] and summarized in Table 1. The RCAs were lighter than NAs with a lower specific gravity and dry-rodded density and more susceptible to abrasion mass loss. Nevertheless, the properties of RCAs were within the typical limits given by the standards and design codes except the water absorption, which was higher [32-36].

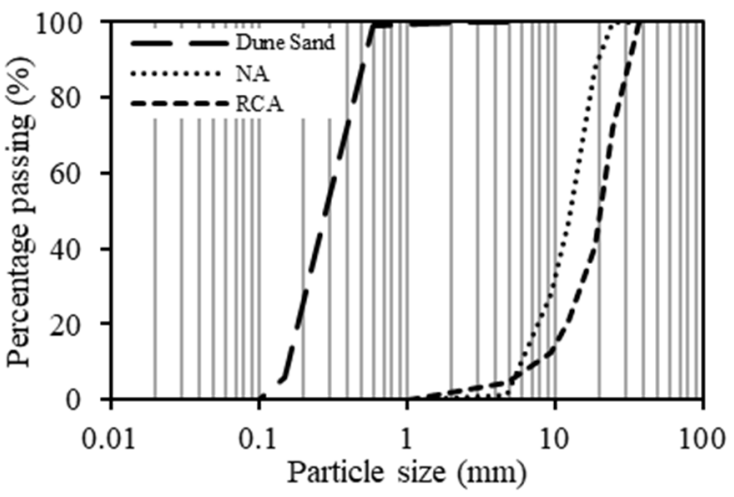

(a)

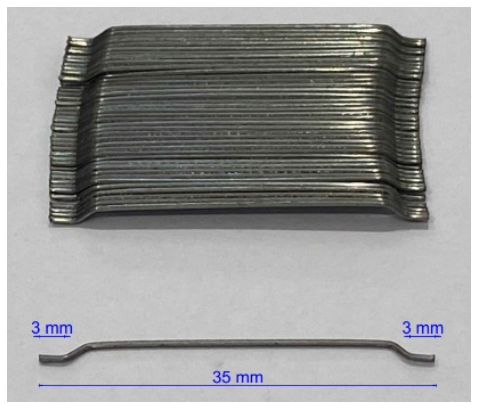

(b)

Figure 1. Materials: (a) Fine and coarse aggregates gradation curves of the (b) steel fibers.

Table 1. Physical properties of fine and coarse aggregates.

\begin{tabular}{cccccccc}
\hline Property & Density & Absorption & Abrasion & $\begin{array}{c}\text { Surface } \\
\text { Area }\end{array}$ & $\begin{array}{c}\text { Soundness } \\
\mathbf{( M g S O}_{\mathbf{4}} \mathbf{)}\end{array}$ & $\begin{array}{c}\text { Specific } \\
\text { Gravity }\end{array}$ & $\begin{array}{c}\text { Fineness } \\
\text { Modulus }\end{array}$ \\
\hline & $\mathbf{( k g / \mathbf { m } ^ { \mathbf { 3 } } )}$ & $\mathbf{( \% )}$ & $\mathbf{( \% )}$ & $\mathbf{( \mathbf { c m } ^ { \mathbf { 2 } } / \mathbf { g } )}$ & $\mathbf{( \% )}$ & - & - \\
\hline Dune sand & 1663 & - & - & 116.8 & - & 2.77 & 1.45 \\
NAs & 1635 & 0.62 & 16 & 2.49 & 1.2 & 2.82 & 6.82 \\
RCAs & 1563 & 6.63 & 32.6 & 2.5 & 2.78 & 2.63 & 7.44 \\
\hline
\end{tabular}

The respective yield strengths of the longitudinal steel bars and steel stirrups used in the beam specimens were $539 \mathrm{MPa}$ and $505 \mathrm{MPa}$. The steel reinforcing bars had a Young's modulus of $200 \mathrm{GPa}$. The steel fibers were made of low-carbon cold drawn round steel wire with hooks at both ends (Figure 1b). The steel fibers were supplied by Bekaert, Dubai, 
United Arab Emirates. They have a typical tensile strength of $1345 \mathrm{MPa}$, Young's modulus of $200 \mathrm{GPa}$, diameter $\left(D_{f}\right)$ of $0.55 \mathrm{~mm}$, length $\left(l_{f}\right)$ of $35 \mathrm{~mm}$, and an aspect ratio $\left(l_{f} / D_{f}\right)$ of 65 [37]. This specific type of steel fiber was the most economical one among others used to improve the splitting tensile strength of concrete [38]. It is worth noting that the data sheet of the manufacturer does not specify a maximum amount of steel fibers to be used in concrete. However, factors such as composition of the concrete, method of placement, and application type governs the maximum steel fibers dosage. In this study, prior to casting of beams, trial mixes were carried out to ensure the workability of the concrete and a homogenous distribution of the steel fibers in the concrete mixture.

\subsection{Mixture Proportioning}

The mix design procedure of ACI 211.1 [39] was employed to develop the concrete control mixture with a design cylinder compressive strength of $f_{c}^{\prime}=30 \mathrm{MPa}$. Table 2 shows the mixture proportions of the five concrete mixes considered in this study. The mixes are labeled RX-SFY, where ' $X$ ' denotes the value of the RCA replacement percentage by mass relative to that of the coarse aggregates, and ' $Y$ ' refers to the value of $v_{f}$. For instance, R100-SF2 is the designation of the mixture made with $100 \%$ RCA with the incorporation of steel fibers at $v_{f}$ of $2 \%$. The total amount of coarse aggregates, cement, dune sand, and water were kept constant in all mixes.

Table 2. Proportions of concrete mixtures $\left(\mathrm{kg} / \mathrm{m}^{3}\right)$.

\begin{tabular}{ccccccc}
\hline Mix Designation & Cement & RCAs & NAs & Dune Sand & Water & Steel Fibers \\
\hline R0-SF0 & 470 & 0 & 1130 & 570 & 230 & 0 \\
R100-SF0 & 470 & 1130 & 0 & 570 & 230 & 0 \\
R100-SF1 & 470 & 1130 & 0 & 570 & 230 & 78 \\
R100-SF2 & 470 & 1130 & 0 & 570 & 230 & 156 \\
R100-SF3 & 470 & 1130 & 0 & 570 & 230 & 234 \\
\hline
\end{tabular}

\subsection{Specimens Preparation}

Concrete components were mixed in a laboratory mechanical mixer. The RCAs and NAs were used in saturated surface dry (SSD) condition to account for their water absorption. Therefore, the amount of water required for the coarse aggregates to achieve their SSD condition was calculated and added to the dry aggregates placed inside the mixer. If existed, steel fibers were then added and mixed with the coarse aggregates for $3 \mathrm{~min}$ to ensure that they were well-dispersed in the concrete mixture. At a later stage, the cement and dune sand were added and mixed with other components for $2 \mathrm{~min}$. Finally, free water was gradually added to the dry components and mixed together for 2 more minutes to ensure a homogeneous and uniform mixture. The slump of fresh concrete was tested directly after the mixing process. The specimens were cast in the designated cubes and cylinders for the concrete material characterization, compacted on a vibration table, demolded after $24 \mathrm{~h}$, and then placed in a water tank for moist curing until the time of testing after 28 days. Three replicate specimens were prepared for each test. The deep beam specimens were cast in a horizontal position using plywood molds inside which the reinforcement steel cages were placed. The concrete mixture was then poured into the wooden molds, compacted by a vibrator, leveled, then finished using a trowel. All concrete deep beam specimens were covered by wetted burlaps and polyethylene sheets. Water curing was applied for seven consecutive days, then the deep beam specimens were air-cured for a minimum of 28 days.

\subsection{Properties of Concrete Mixes}

The workability of the concrete mixes was evaluated by measuring the fresh concrete slump as per the ASTM C143 [40]. Compressive strength tests were performed on $150 \mathrm{~mm}$ cubes and $150 \mathrm{~mm} \times 300 \mathrm{~mm}$ (diameter and height) cylinders in accordance with BS 12390-3 [41] and ASTM C39 [42] procedures, respectively. The modulus of elasticity was 
determined following the ASTM C469 [43] procedure. The splitting tensile strength tests were performed on cylindrical specimens having dimensions of $150 \mathrm{~mm} \times 300 \mathrm{~mm}$ (diameter and height) following the ASTM C496 [44] procedure. Table 3 reports the resulting average values along with the corresponding standard deviation of the 28-day concrete cylinder compressive strength, $f_{c}^{\prime}$, cube compressive strength, $f_{c u}$, splitting tensile strength, $f_{s p}$, and Young's modulus, $E_{c}$.

Table 3. Test results of slump, compressive strength, Young's modulus, and splitting tensile strength.

\begin{tabular}{cccccc}
\hline $\begin{array}{c}\text { Mixture } \\
\text { Designation }\end{array}$ & R0-SF0 & R100-SF0 & R100-SF1 & R100-SF2 & R100-SF3 \\
\hline Slump (mm) & 228 & 183 & 85 & 60 & 20 \\
$f^{\prime}{ }_{c}(\mathbf{M P a}) *$ & $36.4(1.5)$ & $23.6(0.40)$ & $25.8(0.3)$ & $25.6(1.4)$ & $25.0(0.8)$ \\
$f_{c u}(\mathbf{M P a}) *$ & $40.5(1.8)$ & $24.7(1.0)$ & $32.2(0.6)$ & $30.0(1.0)$ & $28.3(0.7)$ \\
$f_{s p}(\mathbf{M P a}) *$ & $3.1(0.2)$ & $2.1(0.2)$ & $3.1(0.1)$ & $3.4(0.2)$ & $4.1(0.6)$ \\
$\boldsymbol{E}_{c}(\mathbf{G P a}) *$ & $34.7(1.8)$ & $19.8(2.4)$ & $21.5(2.9)$ & $20.7(2.5)$ & $21.1(1.6)$ \\
\hline
\end{tabular}

*Values between parentheses represent the standard deviation.

\subsection{Deep Beam Test Specimens}

The experimental program is summarized in Table 4. Seven RC deep beams with web openings were tested. The notations ARX-SFY-S and ARX-SFY were used to designate the beam specimens with and without conventional steel stirrups, where ' $X$ ' is the RCA replacement percentage and ' $Y$ ' is the steel fiber volume fraction $v_{f}$. Two beams were made of NA-based concrete without steel fibers. One of them included minimum conventional steel stirrups while the other one was kept with neither steel stirrups nor steel fibers. Five beams included 100\% RCAs. Out of these five beams, one beam had neither steel stirrups nor steel fibers, one beam had minimum conventional steel stirrups, and three beams contained steel fibers at $v_{f}$ of 1,2 , and $3 \%$. Schematic representations of the test specimens showing the concrete dimensions and the reinforcement layout of beam specimens with and without conventional steel stirrups are illustrated in Figure 2a,b, respectively. All deep beams had a rectangular cross-section of $150 \times 500 \mathrm{~mm}$ (width $\times$ depth) and a total length of $2500 \mathrm{~mm}$. The effective span of the specimen was $2100 \mathrm{~mm}$ including two $400 \mathrm{~mm}$ shear spans. Accordingly, the value of $a / h$ was 0.8 . The beams were designed to fail in shear. The tension steel reinforcement consisted of four No. 25 deformed steel bars each having a nominal cross sectional area $A_{b}=491 \mathrm{~mm}^{2}$. The compression steel reinforcement consisted of two No. 25 deformed steel bars. The depth of the tension steel from the compression face of the beam (d) was $450 \mathrm{~mm}$. The web reinforcement, when employed, consisted of No. 5 smooth steel bars, with $A_{b}=19.6 \mathrm{~mm}^{2}$ each, spaced at $80 \mathrm{~mm}$ in both vertical and horizontal directions. Details of the minimum conventional steel stirrups were decided to satisfy requirements of the ACI 318-14 [10] for deep beams. Additionally, all deep beams had two circular openings, one in each shear span, placed symmetrically about the midpoint of the beam specimens to fully interrupt the natural load path. The center of each opening was located at the midheight of the beam ( $250 \mathrm{~mm}$ below the top surface) and at the middle of the shear span (200 $\mathrm{mm}$ away from the center of the support). This was done to induce an extreme discontinuity in the shear span. The openings had a diameter of $150 \mathrm{~mm}$ which corresponded to $h_{0} / h$ of 0.3 .

\subsection{Test Setup}

The test setup is shown in Figure 3. All beams were tested to failure under two concentrated loads using two actuators. The effective span of the beams was $2100 \mathrm{~mm}$, and the shear span was $400 \mathrm{~mm}$. The distance between the concentrated loads was $1300 \mathrm{~mm}$. Two load cells were used to record the applied loads. In addition, $20 \times 150 \mathrm{~mm}$ (thickness $\times$ width) steel bearing plates were placed under the loading points and at the supports. The tests were initially performed under a load-controlled rate of $0.5 \mathrm{kN} / \mathrm{s}$. When the beam reached approximately $80 \%$ of its anticipated shear capacity, the loading method 

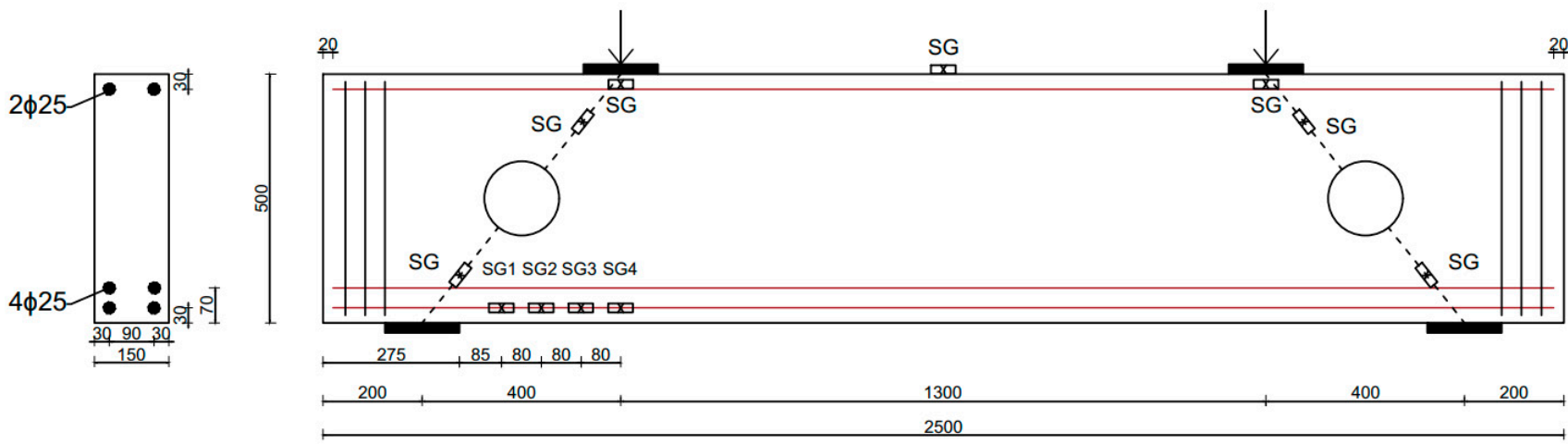

was changed to be displacement-controlled at a rate of $0.6 \mathrm{~mm} / \mathrm{min}$ in an effort to avoid a catastrophic collapse and to capture the post-peak response. The midspan deflection was measured using a linear variable differential transducer (LVDT). The strains in the tension steel within the shear span were measured using four strain gauges (SGs), each having a length of $5 \mathrm{~mm}$. These SGs were bonded to the bottom longitudinal steel reinforcement at a spacing of $80 \mathrm{~mm}$ within the shear span. In each shear span of the beams with steel stirrups, a 5-mm SG was installed on the vertical stirrup next to the opening. The locations of the SGs bonded to the tension steel and stirrups are illustrated in Figure $2 \mathrm{~b}$. The longitudinal concrete strains were measured using three SGs of $60 \mathrm{~mm}$ length bonded to the concrete surface longitudinally at the midspan and under the load plates. Four SGs of $60 \mathrm{~mm}$ length were also bonded to the concrete surface in the diagonal direction in the top and bottom chords of each shear span to measure the concrete strain in the diagonal direction in each chord. The locations of the concrete SGs used in all deep beams are shown in Figure 2a. The measuring tools were connected to a data logger to record the readings simultaneously. The development and propagation of cracks were marked, and the mode of failure was recorded. Digital image correlation (DIC) technique may be used in future research or field applications as an alternative to mechanical measurement devices to facilitate monitoring of surface strains and development of cracks in critical regions of concrete beams with web openings $[45,46]$.

(a)
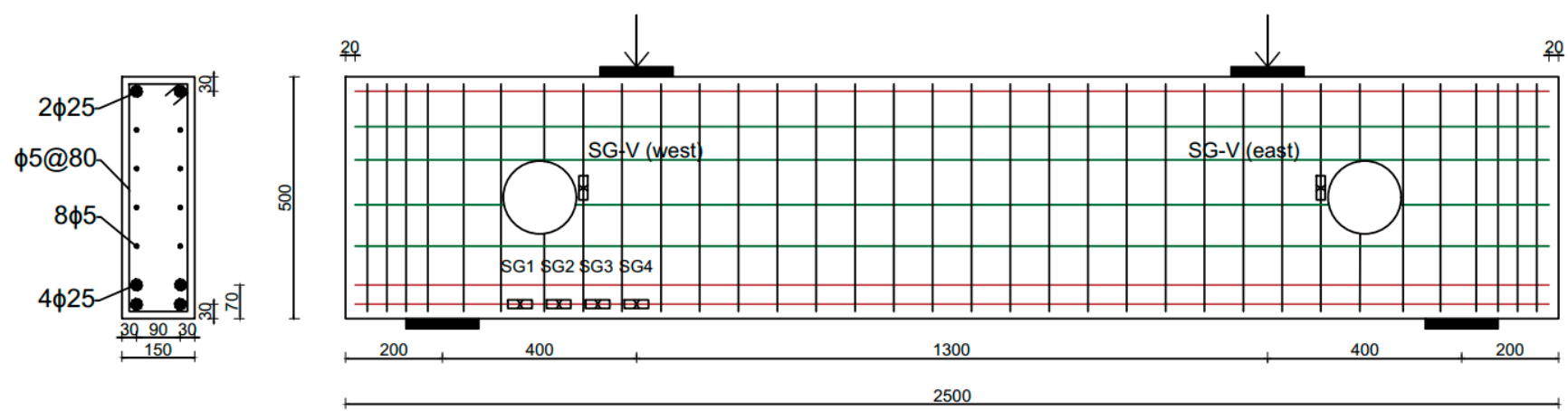

(b)

Figure 2. Details of deep beam specimens (dimensions are in mm): (a) A beam without conventional steel stirrups; (b) a beam with conventional steel stirrups. 
Table 4. Experimental program of the deep beam specimens.

\begin{tabular}{cccc}
\hline $\begin{array}{c}\text { RCAs } \\
(\mathbf{\%})\end{array}$ & $\begin{array}{c}\text { Beam } \\
\text { Designation }\end{array}$ & $\begin{array}{c}\text { Presence of Conventional } \\
\text { Steel Stirrups }\end{array}$ & $\begin{array}{c}\boldsymbol{v}_{f} \\
\mathbf{( \% )}\end{array}$ \\
\hline \multirow{2}{*}{0} & AR0-SF0 & - & - \\
& AR0-SF0-S & $\sqrt{ }$ & - \\
\hline \multirow{2}{*}{100} & AR100-SF0 & - & - \\
& AR100-SF0-S & $\sqrt{ }$ & - \\
& AR100-SF1 & - & 2 \\
& AR100-SF2 & - & 3 \\
\hline
\end{tabular}

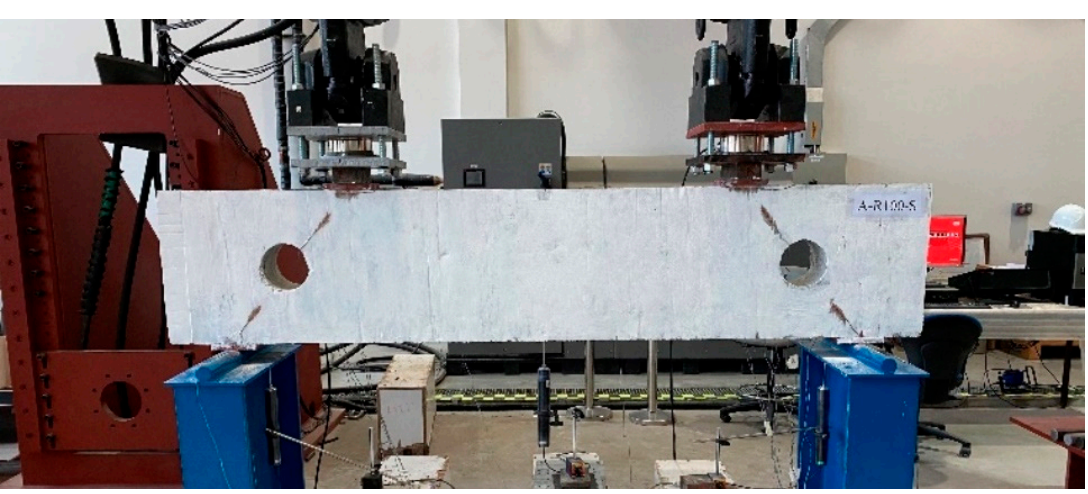

Figure 3. Test setup.

\section{Experimental Results}

The shear performance of the test specimens is evaluated and discussed in this section. The effect of test variables on the deflection response, cracking load, shear capacity, failure mode, and measured strains is elucidated.

\subsection{Deflection Response}

Figure 4a shows the shear load-deflection behaviors of the beams without steel fibers. From this figure, it can be seen that up to a shear load of approximately $80 \mathrm{kN}$, the NA-based beams without conventional steel stirrups, AR0-SF0 and AR100-SF0, had nearly an equal initial stiffness. As the load progressed, specimen AR100-SF0 started to exhibit a lower stiffness than that of AR0-SF0. Specimens AR0-SF0-S and AR100-SF0-S, with conventional steel stirrups, had an equal initial stiffness up to an approximate shear load of $40 \mathrm{kN}$, after which the RCA-based specimen AR100-SF0-S experienced a lower stiffness compared to that of its NA-based counterpart AR0-SF0-S. The conventional steel stirrups improved the stiffness of the beams. The improvement in beam stiffness resulting from the presence of conventional steel stirrups was less pronounced for the RCA-based specimen AR100-SF0-S rather than the NA-based specimen AR0-SF0-S. It seems that the severity of cracks in the RCA-based concrete specimen limited the effect of the conventional steel stirrups on the beam stiffness. Table 5 reports values of the midspan deflection at first visible shear cracking $\left(\Delta_{c r}\right)$ and those at the shear capacity $\left(\Delta_{\max }\right)$. The beams made with $100 \%$ RCAs without steel fibers experienced higher midspan deflections than those of their counterparts made with NAs. This behavior can be ascribed to the reduced Young's modulus of the concrete made with RCAs.

Figure $4 \mathrm{~b}$ shows the shear load-deflection responses of the RCA concrete beams with and without steel fibers. The addition of steel fibers clearly improved the stiffness and the overall performance of the beams made with $100 \%$ RCA. The beams with steel fibers did not experience a significant change in the slope of the deflection response at the time of cracking. This behavior is ascribed to the effectiveness of steel fibers to restrict growth of shear cracks. Values of the midspan deflection at the first visible shear cracking load and at 
the shear capacity of the RCA-based specimens increased by increasing the content of steel fibers (Table 5). Additionally, the stiffness of the beams having steel fibers were better than that of AR100-SF0-S having conventional steel stirrups. In fact, the stiffness of AR100-SF2 and AR100-SF3 almost coincided with that of AR0-SF0-S having NAs and conventional steel stirrups. The presence of steel fibers in the RCA concrete beams with web openings delayed initiation of shear cracks, limited their growth in the post-cracking phase, and hence, improved the beam stiffness. The improved stiffness of the RCA-based beams with fibers would result in less deflections under service load thus improving serviceability of structure.

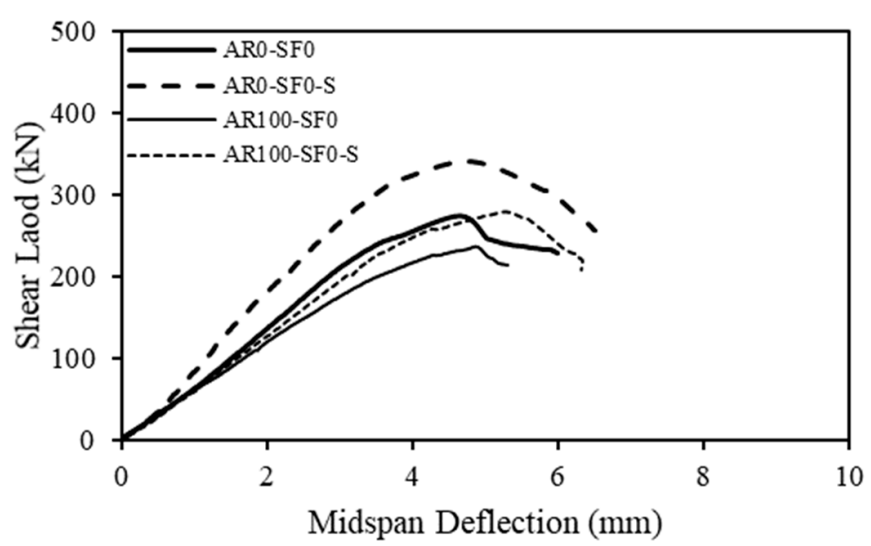

(a)

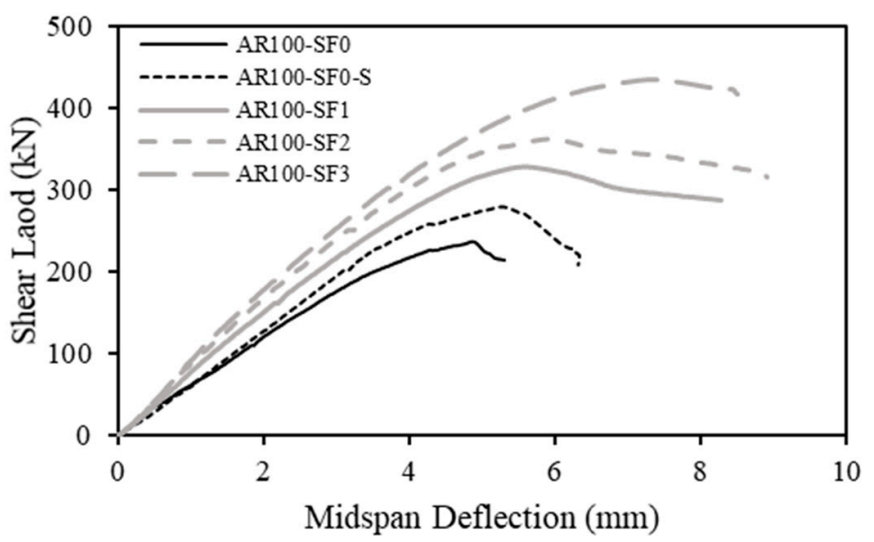

(b)

Figure 4. Shear load versus deflection relationship: (a) Beam specimens without steel fibers; (b) RCA beams with and without steel fibers.

\subsection{Shear Cracking Load and Shear Capacity}

Table 5 summarizes the test results including the first visible shear cracking load, $V_{c r}$, shear capacity, $V_{\max }$, corresponding deflections at first visible shear cracking load and at the shear capacity, values of $V_{c r} / V_{\max }$, and the shear strength gain. The shear cracking load of specimens AR0-SF0-S and AR100-SF0-S with conventional steel stirrups were 30 and $15 \%$ higher than those of AR0-SF0 and AR100-SF0 without stirrups, respectively. Such an increase in the shear cracking load is attributed to the fact that the steel stirrups delay the appearance of shear cracks on the surface. Similarly, the inclusion of conventional steel stirrups increased the shear capacity of specimens AR0-SF0-S and AR100-SF0-S by 25 and $18 \%$, respectively, compared with those of their respective counterparts AR0-SF0 and AR100-SF0. The inclusion of conventional steel stirrups in RC deep beam specimens with openings was less effective in delaying the appearance of shear cracks and improving the shear capacity when 100\% RCA was used. The reduced shear cracking load and strength of the beams with RCAs is ascribed to the reduced mechanical characteristics of the concrete mixes having 100\% RCAs relative to those of the mixes with NAs. The failure mode of the tested beams was governed mainly by concrete properties. It seems that the inferior properties of the RCA-based concrete with web openings diminished the impact of the conventional steel stirrups on the shear cracking load and shear capacity. Specimens with RCAs exhibited insignificant change in values of $V_{c r} / V_{\max }$ ratios compared to those of their counterparts with NAs.

As shown in Table 5, the use of steel fibers increased in the shear cracking load of the RCA beams compared to that of their counterpart specimen AR100-SF0. Such an increase is owed to the improved tensile properties of the mixes with steel fibers. The shear cracking loads of specimens AR100-SF1 and AR100-SF2 made with 1 and 2\% steel fibers were equivalent to and higher than that of their counterpart AR100-SF0-S with conventional steel stirrups, respectively. The shear cracking load of AR100-SF3 ( $\left.v_{f}=3 \%\right)$ was even higher 
than that of AR0-SF0-S made with NAs and conventional steel stirrups. The inclusion of steel fibers remarkably increased the shear capacity of the beams made with $100 \%$ RCAs. The RCA beams with steel fibers exhibited lower values of $V_{c r} / V_{\max }$ compared to those of the beams without fibers. This behavior occurred because RCA beams with steel fibers exhibited higher gain in the shear capacity relative to the gain in the shear cracking load. Specimens AR100-SF1, AR100-SF2, and AR100-SF3 experienced shear strength gains of 39,53 , and $84 \%$, respectively, compared to strength gain experienced by AR100-SF0. The improvement in the shear strength of the RCA beams with steel fibers is attributed to the enhanced post-cracking endurance of the concrete mixtures with steel fibers and the ability of the steel fibers to limit growth and propagation of shear cracks in concrete deep beams with web openings. Specimen AR100-SF1 made with 1\% of steel fibers experienced higher shear strength than that of AR100-SF0-S having conventional steel stirrups. Specimen AR100-SF2 with 2\% steel fibers exhibited a shear capacity even higher than that of the NA-based specimen AR0-SF0-S having conventional steel stirrups. These results indicate that it is possible to use steel fibers in concrete deep beams with $100 \%$ RCAs and web openings in replacement of the minimum conventional steel stirrups required by ACI 318-14 [10].

Table 5. Test results.

\begin{tabular}{|c|c|c|c|c|c|c|}
\hline \multirow{2}{*}{ Specimen } & \multicolumn{2}{|c|}{ Shear Cracking Stage } & \multicolumn{2}{|c|}{ Ultimate Stage } & \multirow{2}{*}{$\frac{V_{c r}}{V_{\max }}$} & \multirow{2}{*}{$\begin{array}{c}\text { Gain in Shear } \\
\text { Capacity }(\%)\end{array}$} \\
\hline & $V_{c r}(\mathbf{k N})$ & $\Delta_{c r}(\mathrm{~mm})$ & $V_{\max }(\mathrm{kN})$ & $\Delta_{\max }(\mathrm{mm})$ & & \\
\hline AR0-SF0 & 100 & 1.5 & 273 & 4.7 & 0.37 & - \\
\hline AR0-SF0-S & 130 & 1.4 & 341 & 4.8 & 0.38 & $25 *$ \\
\hline AR100-SF0 & 87 & 1.5 & 237 & 4.9 & 0.37 & - \\
\hline AR100-SF0-S & 100 & 1.6 & 279 & 5.3 & 0.36 & $18^{* *}$ \\
\hline AR100-SF1 & 100 & 1.3 & 329 & 5.6 & 0.30 & $39 * *$ \\
\hline AR100-SF2 & 120 & 1.4 & 362 & 6.0 & 0.33 & $53^{* *}$ \\
\hline AR100-SF3 & 140 & 1.5 & 435 & 7.4 & 0.32 & $84^{* *}$ \\
\hline
\end{tabular}

* Relative to the shear capacity of AR0-SF0. ${ }^{* *}$ Relative to the shear capacity of AR100-SF0.

\subsection{Crack Pattern and Failure Mode}

Figure 5a-g show the crack patterns observed in the tested deep beam specimens at failure. All specimens failed in shear. In specimen AR0-SF0, diagonal tension cracks developed in the bottom chords and then progressed tangentially to the inner side of the openings, crossing in the top chord toward the load points after further incremental loading. At approximately $75 \%$ of the load capacity, another diagonal crack developed in the top chord in both shear spans. At the time of failure, two independent diagonal splitting cracks formed in the top and bottom chords of the west shear span causing a frame-type mode of failure (Figure 5a). Specimen AR100-SF0 initially exhibited diagonal tension cracks crossing the center of the openings in the top and bottom chords of the shear spans (Figure 5c). These cracks stopped propagating after a small advancement in the load and did not cause failure. After further increase in the load, the beam failed in a frame-type mode of failure due to development of two diagonal splitting cracks independently in the top and bottom chords of the shear spans causing failure (Figure $5 c$ ).

In specimen AR0-SF0-S and AR100-SF0-S having conventional steel stirrups, diagonal tension cracks initially formed in the west shear span crossing the center of the opening. As the load progressed, two independent cracks developed in the top and bottom chords. Further increase in the load caused development of additional cracks parallel to the two cracks initiated earlier in each chord forming struts. The beam eventually failed due to crushing of the struts in each chord (Figure $5 b, d$ ). 

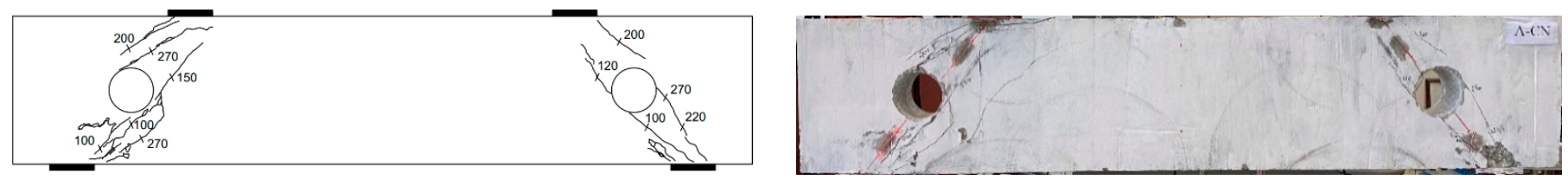

(a)
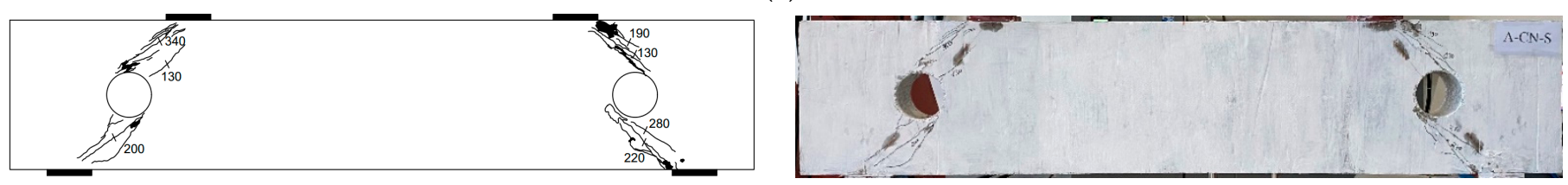

(b)
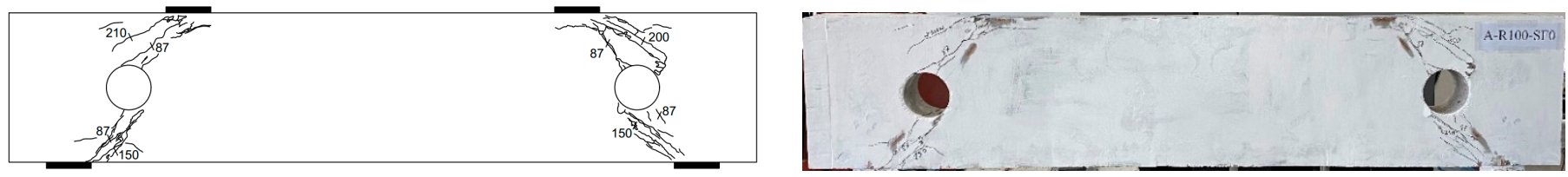

(c)
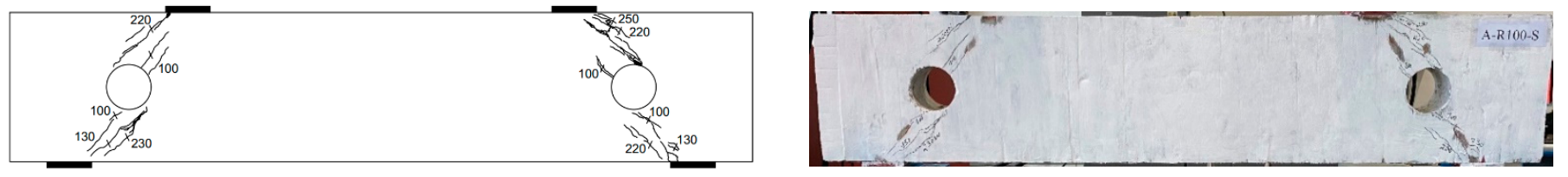

(d)
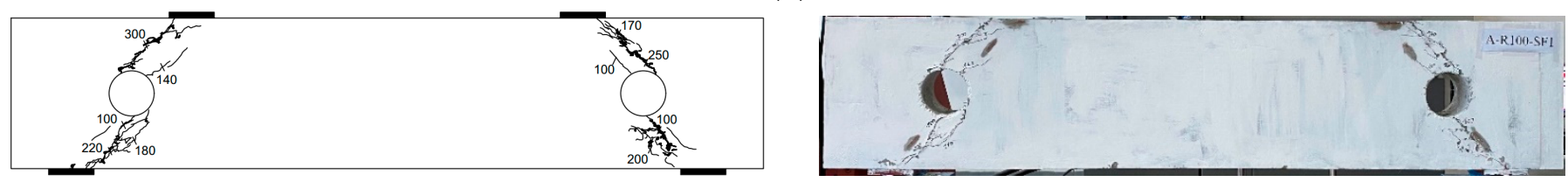

(e)
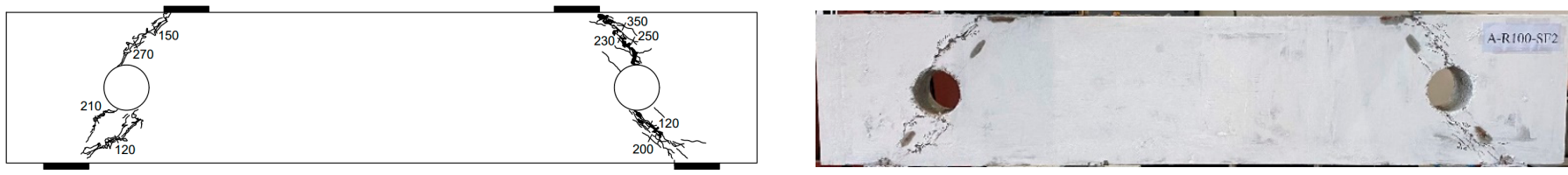

(f)
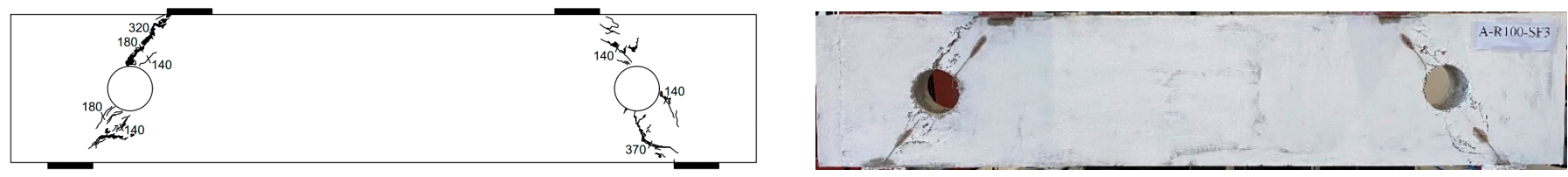

$(\mathrm{g})$

Figure 5. Crack pattern at failure: (a) AR0-SF0; (b) AR0-SF0-S; (c) AR100-SF0; (d) AR100-SF0-S; (e) AR100-SF1; (f) AR100-SF2; (g) AR100-SF3.

Specimens with steel fibers, AR100-SF1, AR100-SF2, and AR100-SF3, exhibited initially fine cracks crossing the center of the opening (Figure $5 \mathrm{e}-\mathrm{g}$ ). The presence of steel fibers hindered further propagation of these diagonal shear cracks. As the load progressed, two independent cracks developed in the top and bottom chords. Further increase in 
load resulted in development of multiple cracks parallel to the originally developed ones forming struts. Finally, the beams failed by crushing of the struts developed in chords (Figure 5e-g). It should be noted that specimen AR100-SF3 exhibited fewer cracks (i.e., the severity of cracks was less pronounced), as shown in Figure $5 \mathrm{~g}$. This behavior was mainly due to the inclusion of a higher content of steel fibers $\left(v_{f}=3 \%\right)$. Reducing the severity of cracks results in better serviceability performance. Failure of the beam was due to loss of shear integrity caused by excessive widening of the diagonal crack in the top chord of the west shear span and due to local crushing observed in multiple locations along the struts developed in the chords (Figure $5 \mathrm{~g}$ ).

\subsection{Sirrup Strains}

Figure 6 shows the shear load-stirrup strain relationship. The SG in one of the vertical stirrups of beam AR100-SF0-S malfunctioned during testing. All the measured strain in the vertical stirrups were below yielding. The stirrup strain response included two stages, namely, pre-cracking and post-cracking stages. Initially, the steel stirrups showed no or minimal strains. Following cracking, the stirrup strain increased in a linear fashion until failure. The rate of increase of the stirrup strain of the two vertical stirrups of beam AR0SF0-S was insignificantly different. The stirrup strain increased at a higher rate in beam AR100-SF0-S with 100\% RCAs compared to that of AR0-SF0-S with NAs. The higher rate of increase of stirrup strain in the case on RCA-based beam signifies a reduced contribution of the recycled aggregates concrete to the shear resistance compared to that of the NA-based counterpart. The reduced contribution of RCA-based concrete to the shear resistance can be ascribed to its inferior properties relative to those of NA-based concrete.

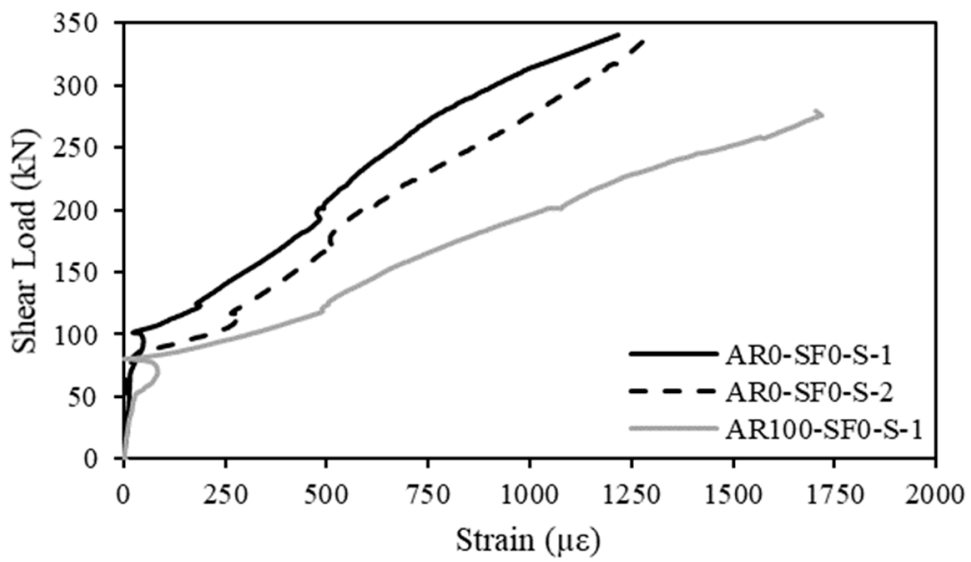

Figure 6. Shear load versus maximum stirrup strain relationships.

\subsection{Tensile Steel Strains}

Figure 7 presents results of strain measurements in the longitudinal steel reinforcing bars at four different loading stages. Strain readings in specimens AR0-SF0 and AR100-SF1 at $400 \mathrm{~mm}$ away from the center of the support were missing due to malfunction of the strain gauge before testing. Values of the maximum steel strains measured at peak load are given in Table 6. The tension steel did not reach the yield strain $\left(\varepsilon_{\text {yield }}=2695 \mu \varepsilon\right)$ except in one location in specimen AR100-SF3 at the distance of $240 \mathrm{~mm}$ away from the center of support, as shown in Figure $7 \mathrm{~g}$. The strain in the tensile steel in other locations of specimen AR100-SF3 was below yielding. From Figure 7, it can be seen that as the load increased, the steel strains increased almost uniformly within the shear span up to $75 \%$ of the shear capacity verifying the behavior of a deep beam action (strut and tie action). Due to the severity of cracks in the bottom chord below the openings at the distance of $160 \mathrm{~mm}$ and $240 \mathrm{~mm}$ at the onset of failure, the strain in the steel at $100 \%$ of the shear capacity was higher at these locations relative to that measured at other locations away from the openings and the cracks. 


\subsection{Concrete Strains}

The maximum compressive concrete strains in the longitudinal and diagonal directions measured at the peak load are given in Table 6. Excluding specimen AR0-SF0, it can be seen that for the specimens without steel fibers, the maximum diagonal concrete strains were higher than those measured in the longitudinal direction indicating higher concrete deformations in the diagonal direction, possibly due to the presence of the web opening and shear cracking. In contrast, steel fiber-reinforced RCA specimens, except AR100SF2, exhibited lower diagonal compressive concrete strains than those measured in the longitudinal direction. It seems that the presence of steel fibers reduced the deformation in the diagonal direction relative to those of the longitudinal direction due to the reduced severity of shear cracking. Steel fiber-reinforced RCA specimens tended to exhibit higher diagonal and longitudinal concrete strains than those of their counterparts without steel fibers. This behavior can be attributed to the increase in the load-carrying capacity of the beams with steel fibers, which accommodated for additional concrete strain prior to failure.

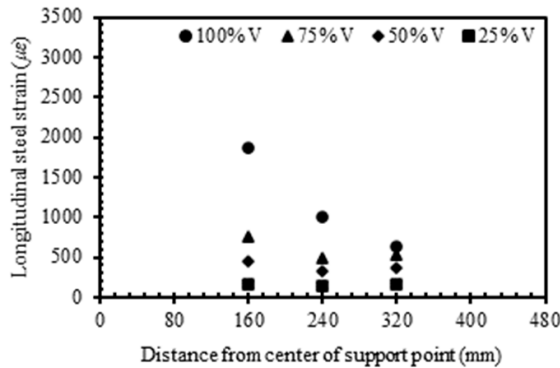

(a)

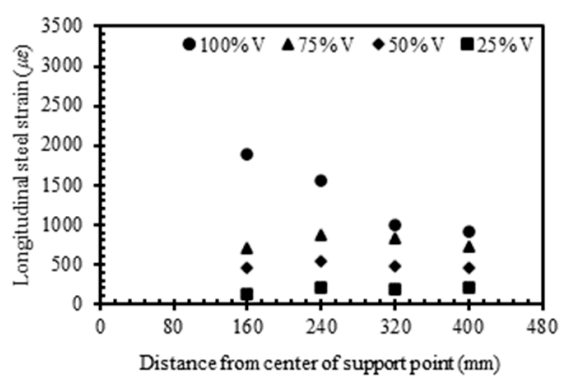

(d)

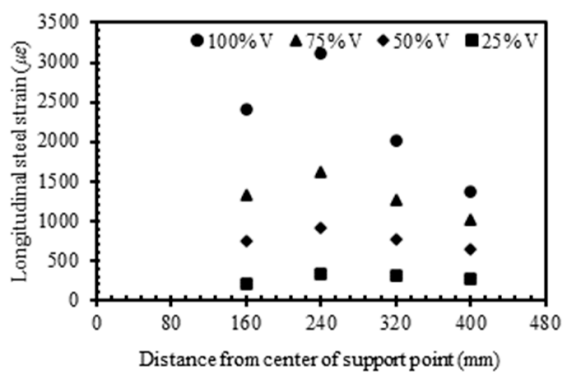

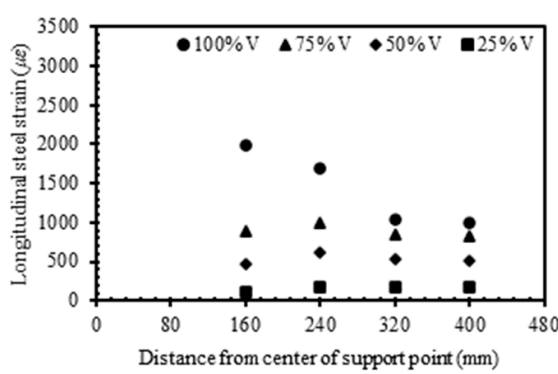

(b)

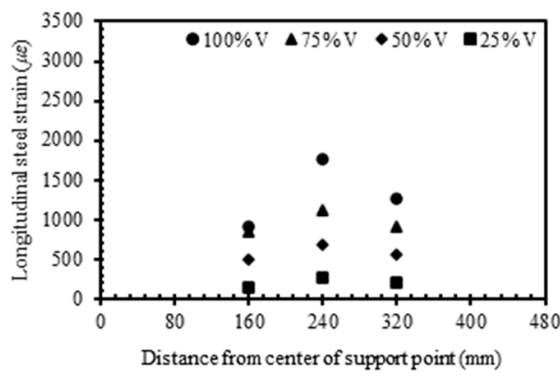

(e)

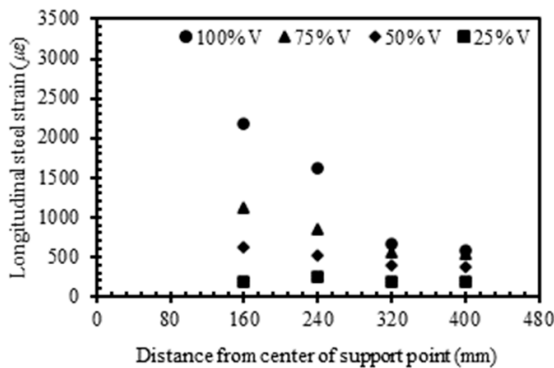

(c)

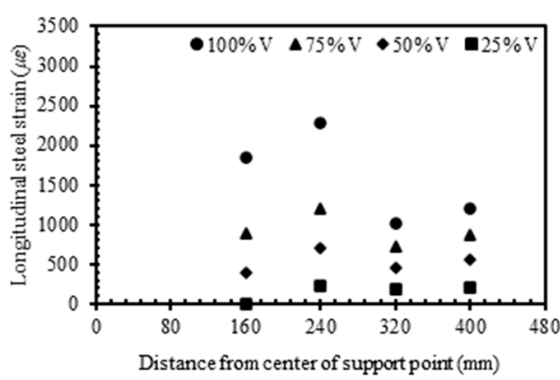

$(\mathbf{f})$

(g)

Figure 7. Steel strain profile: (a) AR0-SF0; (b) AR0-SF0-S; (c) AR100-SF0; (d) AR100-SF0-S; (e) AR100SF1; (f) AR100-SF2; (g) AR100-SF3. 
Table 6. Maximum strains measured at peak load.

\begin{tabular}{ccccc}
\hline \multirow{2}{*}{ Specimen } & \multicolumn{2}{c}{ Concrete Strain $(\mu \varepsilon)$} & Max. Longitudinal & \\
\cline { 2 - 3 } & $\begin{array}{c}\text { Max. Longitudinal } \\
\text { Strain }\end{array}$ & $\begin{array}{c}\text { Max. Diagonal } \\
\text { Strain }\end{array}$ & $\begin{array}{c}\text { Steel Strain } \varepsilon_{\boldsymbol{s}}(\boldsymbol{\mu \varepsilon}) \\
\varepsilon_{\boldsymbol{s}} / \varepsilon_{\boldsymbol{y}}\end{array}$ \\
\hline AR0-SF0 & 1470 & 616 & 1859 & 0.69 \\
AR0-SF0-S & 1062 & 1552 & 1990 & 0.74 \\
AR100-SF0 & 1126 & 1672 & 2182 & 0.81 \\
AR100-SF0-S & 1102 & 1584 & 1890 & 0.70 \\
AR100-SF1 & 2532 & 1144 & 1758 & 0.65 \\
AR100-SF2 & 2120 & 2513 & 2282 & 0.85 \\
AR100-SF3 & 3211 & 1965 & $3109 *$ & 1.15 \\
\hline *In one point only within the shear span. & & &
\end{tabular}

${ }^{*}$ In one point only within the shear span.

\section{Analytical Prediction}

Methods of analysis for shear strength prediction of RC deep beams containing openings are examined in this section. The shear capacities of the deep beam specimens tested in this study were derived based on three different analytical models proposed by Kong and Sharp [47], Shanmugam and Swaddiwudhipong [27], and Ray and Reddy [48]. Structural idealization of reinforced concrete deep beams with openings is shown in Figure 8. The shear capacity of steel fiber-reinforced deep beams with openings, $V_{n}$, can be estimated using Equation (1). In this equation, $V_{c}=$ concrete contribution to the shear capacity, and $V_{s}=$ contribution of steel bars to the shear resistance. The value of $V_{c}$ is mainly influenced by the mechanical properties of concrete and $a / d$ whereas that of $V_{S}$ is affected by the properties and location of the steel reinforcing bars crossed by the critical shear crack.

$$
V_{n}=V_{c}+V_{s}
$$

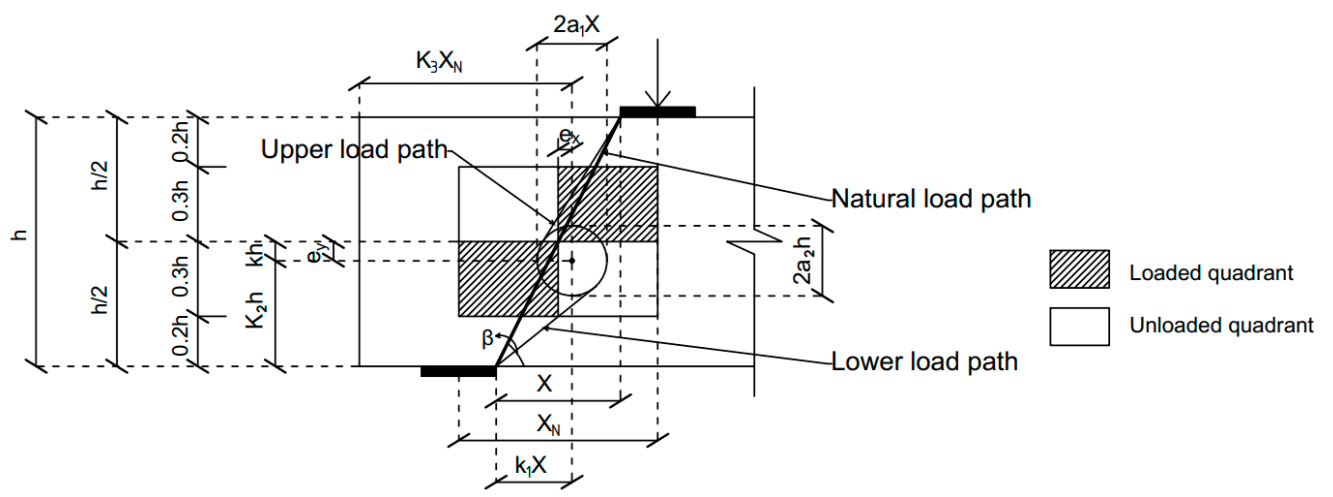

Figure 8. Structural idealization of deep beams with openings.

According to Kong and Sharp [47], the shear strength of a deep beam is significantly affected only when the opening interrupts the natural load path, which is considered in this study as the line joining edges of the load and support plates. The load transmission path is then divided, the primary path being the one traversing below the opening. In this model, the applied load is assumed to be transmitted to the support mainly by a lower path and partly by an upper path (Figure 8). Based on this structural idealization, the researchers proposed Equation (2) to estimate the shear capacity of RC deep beams with an opening that interrupts the natural load path. In this equation, $K_{1}$ and $K_{2}=$ coefficients defining the position of opening, $a_{1}$ and $a_{2}=$ coefficients defining the opening size, $X=$ clear shear span, $f_{s p}=$ cylinder-splitting tensile strength of concrete, $\lambda=$ empirical coefficient, equal to 1.5 for web bars and 1 for main bars, $A=$ area of an individual web as well as main bar, $y_{1}=$ depth at which a typical bar intersects a potential critical diagonal crack (upper and lower load path in Figure 8), $\alpha_{1}=$ angle of inclination between a typical bar and a potential diagonal crack depending on the failure mode (upper and lower load path in Figure 8), $C_{1}=1.4$ 
for normal weight concrete, $C_{2}=130 \mathrm{~N} / \mathrm{mm}^{2}$ for plain round bars and $300 \mathrm{~N} / \mathrm{mm}^{2}$ for deformed bars, $h=$ total depth of the beam, and $b=$ width of the beam.

$$
V_{n}=C_{1}\left[1-0.35 \frac{\left(K_{1}+a_{1}\right) X}{\left(K_{2}-a_{2}\right) h}\right] \mathbf{f}_{s p} b\left(K_{2}-a_{2}\right) h+\sum \lambda C_{2} A \frac{y_{1}}{h} \sin ^{2} \alpha_{1}
$$

Shanmugam and Swaddiwudhipong [27] proposed Equation (3) as a modified form of Kong and Sharp's [47] semi-empirical formula based on further test results considering the enhanced properties in the case of fiber reinforced concrete deep beams. Equations (4)-(6) were utilized to calculate the required components of Equation (3), where $n=1.1, f_{1}=$ reduction factor to account for the size of openings, $f_{2}=$ reduction factor to account for the degree of interruption of the opening. $k=$ the distance of the center of opening from the beam axis, $r=$ factor depending on the location of the center of opening which is equal to 1 in case the center of opening is located in the unloading quadrants and 2 in case the center of opening is located in the loaded quadrants. The remaining notations are defined in the previous paragraph similarly to the Sharp and Kong Equation (2).

$$
\begin{gathered}
V_{n}=C_{1} f_{1} f_{2}\left[1-0.35 \frac{X}{h}\right] f_{s p}^{n} b h+\sum \lambda C_{2} A \frac{y_{1}}{h} \sin ^{2} \alpha_{1} \\
f_{1}=\left(1-\mathbf{a}_{1}\right)\left(1-\frac{a_{2}}{0.6}\right) \\
f_{2}=\xi+2\left(k_{2}\right)^{r} \sqrt{\frac{\left(k_{1}-k_{2}\right)^{2}}{\left[\left(a_{1} X\right)^{2}+\left(a_{2} h\right)^{2}\right]}} \leq 1 \\
\xi=0.6-2 k \geq 2
\end{gathered}
$$

Ray and Reddy [48] proposed Equation (7) to predict the ultimate shear strength of reinforced concrete deep beams with web openings. The researchers split $V_{s}$ into two components, $V_{d}$ to account for the dowel action and $V_{w}$ to account for the steel stirrups. In their study, the researchers postulated that the applied load may be assumed to be transmitted to the supports through the natural load path connecting edges of the load and support plates even if the opening interferes with it. Equations (8)-(17) were utilized to calculate the required components of Equation (7). In these equations, $\psi_{s}=0.65, \psi_{w}=0.5$, $A_{s}=$ area of tension steel, $A_{w}=$ area of individual web steel, $f_{y}=300 \mathrm{MPa}$ for deformed bars and $130 \mathrm{MPa}$ for smooth bars, $f_{c}^{\prime}=$ cylinder compressive strength of the concrete, $f_{s p}=$ cylinder-splitting tensile strength of concrete, $b=$ beam width, $h=$ beam depth, $c$ is a parameter dependent on the concrete compressive strength, and tensile splitting strength, $\lambda_{1}, \lambda_{2}$, and $\lambda_{3}$ are factors that account for the opening size and location, $\alpha=$ angle of inclination of web bar with horizontal, $\beta=$ angle of inclination of the natural load path, $X=$ clear shear span, $X_{N}=$ nominal shear span, $a_{x}=$ width of the opening, $a_{y}=$ height of the opening, $e_{x}$ and $e_{y}=$ eccentricities of the opening, $K_{2}$ and $K_{3}=$ coefficients defining the opening location. $m$ is the ratio of path length intercepted to total path length along the natural load path.

$$
\begin{gathered}
V_{n}=V_{c}+\left(V_{d}+V_{w}\right) \\
V_{c}=\frac{c b h\left(\lambda_{1} \lambda_{2} \lambda_{3}\right)}{\sin \beta \cos \beta(\tan \beta+\tan \varphi)} \\
V_{d}=\left(\psi_{s} A_{s} f_{y}\right)\left[\frac{\tan \beta \tan \varphi-1}{\tan \beta+\tan \varphi}\right] \\
V_{w}=\psi_{w} \sum A_{w} f_{y}\left[\frac{\sin \alpha \cot \beta+\cos \alpha}{\tan \beta+\tan \varphi) /(\tan \beta \tan \varphi)}\right. \\
\left.-\frac{\cos (1-\tan \alpha \tan \beta)}{\tan \beta+\tan \varphi}\right] \\
c=\sqrt{\frac{f_{c} f_{s p}}{2}}
\end{gathered}
$$




$$
\begin{gathered}
\tan \varphi=\frac{\left(f f_{c}-f_{s p}\right)}{2 \sqrt{f_{c} f_{s p}}} \\
\lambda_{1}=\left\{\begin{array}{cc}
1-\frac{K_{3} X_{n}}{3 K_{2} h} & \text { for } K_{3} X_{N}<K_{2} h \\
\frac{2}{3} & \text { for } K_{3} X_{n N} \geq K_{2} h \\
\lambda_{2}= & 1-m
\end{array}\right.
\end{gathered}
$$

Table 7 shows a comparison of the shear capacities predicted analytically with those obtained from the tests conducted in this study. All models overestimated the shear capacity of the beams without steel fibers. This behavior was more evident in the absence of conventional steel stirrups. The deviation from experimental results was in the range of 32 to $49 \%$ for the beams without conventional steel stirrups and 9 to $30 \%$ for the beams with internal steel stirrups. In contrast, the models tended to provide reasonable or conservative prediction for the shear capacity of the RC deep beams made with $100 \%$ RCAs and steel fibers. Predicted results of the beams with steel fibers based on the analytical approach of Kong and Sharp [47] were within a 12\% error band. The analytical model by Shanmugam and Swaddiwudhipong [27] tended to overestimate the value of the shear capacity of the beams with steel fibers by up to $17 \%$. Predictions of the model by Ray and Reddy [48] for the beams with steel fibers were conservative with predicted-to-measured shear capacity

\begin{tabular}{|c|c|c|c|c|c|c|c|}
\hline \multirow[b]{2}{*}{ Specimen } & \multirow[b]{2}{*}{$\begin{array}{c}\text { Experimental } \\
\text { Results } \\
V_{\max }(\mathrm{kN})\end{array}$} & \multicolumn{3}{|c|}{ Analytical Results $V_{n}(\mathrm{kN})$} & \multicolumn{3}{|c|}{ Ratio $\left(V_{n} / V_{\max }\right)$} \\
\hline & & $\begin{array}{c}\text { Kong and } \\
\text { Sharp } \\
\text { [47] }\end{array}$ & $\begin{array}{c}\text { Shanmugam and } \\
\text { Swaddiwudhipong } \\
{[27]}\end{array}$ & $\begin{array}{c}\text { Ray and } \\
\text { Reddy } \\
{[48]}\end{array}$ & $\begin{array}{l}\text { Kong and } \\
\text { Sharp } \\
{[47]}\end{array}$ & $\begin{array}{c}\text { Shanmugam and } \\
\text { Swaddiwudhipong } \\
\text { [27] }\end{array}$ & $\begin{array}{c}\text { Ray and } \\
\text { Reddy } \\
{[48]}\end{array}$ \\
\hline AR0-SF0 & 273 & 360 & 386 & 383 & 1.32 & 1.42 & 1.40 \\
\hline AR0-SF0-S & 341 & 371 & 397 & 390 & 1.09 & 1.16 & 1.14 \\
\hline AR100-SF0 & 237 & 338 & 353 & 326 & 1.43 & 1.49 & 1.38 \\
\hline AR100-SF0-S & 279 & 349 & 364 & 333 & 1.25 & 1.30 & 1.19 \\
\hline AR100-SF1 & 329 & 360 & 386 & 321 & 1.09 & 1.17 & 0.98 \\
\hline AR100-SF2 & 362 & 367 & 396 & 317 & 1.01 & 1.10 & 0.87 \\
\hline AR100-SF3 & 435 & 382 & 420 & 307 & 0.88 & 0.97 & 0.71 \\
\hline Average & & & & & 1.15 & 1.23 & 1.10 \\
\hline Std Dev * & & & & & 0.19 & 0.18 & 0.26 \\
\hline $\operatorname{COV}(\%)$ & & & & & 16 & 15 & 24 \\
\hline
\end{tabular}
$\left(V_{n} / V_{\max }\right)$ of 0.71 to 0.98 .

Table 7. Comparison between analytical and experimental results.

* Standard deviation.

\section{Discussion}

Despite the substantial environmental benefits that can be obtained by using RCAs in the construction industry as an alternative to NAs, they are not commonly accepted by the engineering community or code provisions to produce structural concrete elements due to the inferior properties of RCA-based concrete mixtures. The uncertainty in satisfying structural performance requirements of a structural concrete beam made with RCAs and steel fibers increases in the presence of openings and/or discontinuity regions. The addition of steel fibers has great potential to improve the properties of concrete mixtures made with RCAs. Although the addition of steel fibers would result in a direct cost increase, there is a potential of reducing or eliminating the use of conventional shear reinforcement in large-scale RC beams, which would result in a direct and indirect cost savings. Practitioners 
should consider a balance between structural performance requirements, environmental benefits, and associated costs. Such an analysis requires identification of quantifiable measures and criteria for performance evaluation.

This research represents the first work on the structural shear behavior of recycled aggregates RC deep beams with openings containing steel fibers. It focuses on the structural aspect of the tested beams. It also examines the accuracy and validity of published analytical models to predict the structural load capacity of such a complex problem. In terms of the structural performance, the load capacity determined from laboratory tests is considered an essential quantifiable measure for structural performance evaluation. Experimental results of the current study indicated that the use of $1 \%$ steel fiber volume fraction in a deep beam with openings made with 100\% RCAs without conventional steel stirrups was sufficient to offset the strength reduction caused by full replacement of NAs with RCAs and restore $96 \%$ of the original shear capacity of a baseline beam made with NAs and conventional steel stirrups. This is an important finding for practitioners and researchers. The three analytical models examined in the current study tended to overestimate the shear capacity of the tested beams without steel fibers with a predicted-to-measured shear capacity in the range of 1.09 to 1.49. For the RCA beams containing openings and steel fibers, the models tended to provide reasonable predictions with a predicted-to-measured shear capacity in the range of 0.71 to 1.17 . Generally, the average predicted-to-measured shear capacity was in the range of 1.10 to 1.23 with a standard deviation of 0.18 to 0.26 and a coefficient of variation of 15 to $24 \%$. The analytical results presented in the current study will raise awareness of practitioners and researchers of the accuracy of published analytical models to predict the shear capacity of recycled aggregates concrete deep beams containing openings with and without steel fibers.

Although the financial and environmental aspects are beyond the scope of the current study, Table 8 shows typical quantifiable measures that could help practitioners and researchers to evaluate environmental benefits and associated costs of RC structures made with RCAs and steel fibers. The environmental impact of the alternative materials can be quantified by evaluating their global warming potential (GWP) values published in the literature [49-54]. From Table 8, it is evident that the use of RCAs along with steel fibers in replacement of NAs and conventional steel stirrups results in a significant reduction in GWP. The direct cost of RCAs is approximately $20 \%$ lower than that of NAs whereas the unit price of steel fibers is approximately 35\% higher than that of conventional steel including the cost of steel fabrication. The economic analysis should, however, include other factors that would affect the cost benefit analysis such as the landfill space saved, reduction in construction time, lifting of reinforcing bars to upper floors, service life of the structure, and other labor- and indirect-related costs. The total cost saving in construction due to the use of steel fibers in replacement of conventional steel reinforcing bars can be as high as 30\% [55]. Previous studies have also verified that the extra cost caused by the inclusion of steel fibers could be counteracted significantly by quantified sustainable benefits of RCAs in an optimum concrete mixture [56-58]. Future research should focus on studying the interaction between the structural performance, environmental benefits, and associated costs using quantifiable measures and life cycle assessment concepts.

Table 8. Cost and GWP values of the alternate materials used in the beams [49-54].

\begin{tabular}{ccc}
\hline Material & $\begin{array}{c}\text { Cost } \\
\text { (USD/kg) }\end{array}$ & $\begin{array}{c}\text { GWP } \\
(\mathbf{k g ~ C O} \mathbf{e q}) / \mathbf{k g}\end{array}$ \\
\hline Natural aggregates (NAs) & $0.00675-0.00953$ & $0.0052-0.0314$ \\
Recycled concrete aggregates (RCAs) & $0.0054-0.0081$ & $6.67 \times 10^{-4}-7.44 \times 10^{-3}$ \\
Conventional steel reinforcement & $0.72-0.84$ & 0.9052 \\
Fabrication of steel cages & $0.22-0.576$ & 0.102 \\
Steel fibers & 1.62 & 0.771 \\
\hline
\end{tabular}




\section{Limitations and Future Research Directions}

This study provided an insight into the structural performance of recycled aggerates $\mathrm{RC}$ deep beams containing web openings and steel fibers. The results of the present investigation are limited to RC deep beam specimens having specific dimensions, opening size/location, reinforcement details, and material properties as reported in this paper. Available codes and standards do not offer a closed form-solution to predict the capacity of such a complex problem. The analytical investigation conducted in this study revealed large variation in the accuracy of the available models. The predicted-to-measured shear capacity was in the range of 0.71 to 1.49 . In addition, published models are not capable of predicting the deflection response of RC deep beam specimens with openings. Future research should focus on the development of numerical simulation models capable of predicting the nonlinear structural behavior of RC deep beams made with RCA and steel fibers. The development of such numerical simulation models requires development of new concrete constitutive laws that take into consideration the effect of RCAs and steel fibers. Published material characterization data can be employed to develop an idealized tensile softening tension function for concrete made with RCAs and different steel fiber volume fractions. Experimental data of the beams tested in the current study can be used to validate future numerical simulation models. Validated simulation models can be used as a numerical platform to investigate the effect of a wider range of parameters and acquire data difficult to measure in the laboratory. Future research should employ life cycle cost analysis and assessment techniques using well-defined quantifiable measures to obtain an improved understanding of the interrelations between the structural performance, environmental benefits, and associated costs of unusual RC structures made with RCAs and steel fibers.

\section{Conclusions}

The behavior of RC deep beams with web openings made with $100 \%$ RCAs was investigated in this paper and compared to that of similar beams made with NAs with and without the minimum conventional steel stirrups. The possibility of using steel fibers as a replacement to the minimum conventional steel stirrups in RC deep beams with web openings made with $100 \%$ RCAs was examined. The shear capacities measured experimentally were compared to predictions of models published in the literature. The following conclusions are drawn.

- Reinforced concrete deep beams with web openings made with $100 \%$ RCAs exhibited 13 to $18 \%$ reductions in the shear capacity relative to those of their counterparts made with NAs. The use of RCAs rather than NAs in RC deep beams with web openings increased the beam deflection at service and ultimate loads.

- The deep beams with conventional steel stirrups or steel fibers failed by crushing of the concrete struts in the top and bottom chords of the openings. Other deep beams without conventional steel stirrups or steel fibers failed due to formation of two independent diagonal splitting cracks in the chords above and below the openings (i.e., frame-type mode failure).

- The inclusion of conventional steel stirrups in RC deep beam specimens with openings was less effective in improving the shear response when 100\% RCAs was used. The use of the minimum conventional steel stirrups increased the shear capacity of the tested beams made with NAs and RCAs by 25 and $18 \%$, respectively.

- The inclusion of steel fibers in the RCA deep beams with web openings at volume fractions of 1,2 , and $3 \%$ resulted in 39,53 , and $84 \%$ respective increases in the shear capacity relative to that of the control RCA-based beam without steel stirrups nor steel fibers.

- The use of $1 \%$ steel fiber volume fraction in the deep beam specimen with openings made with $100 \%$ RCAs without steel stirrups was sufficient to restore $96 \%$ of the original shear capacity of the NA-based beam having conventional steel stirrups.

- The analytical investigation revealed large variation in the accuracy of published analytical models. The predicted-to-measured shear capacity of the tested beams was 
in the range of 0.71 to 1.49 . Although published analytical models tended to provide reasonable/conservative prediction for the shear capacity of RCA-based deep beams with web openings and steel fibers, they overestimated that of the beams without steel fibers. Predictions of the model by Kong and Sharp [47] for the deep beams with web openings made with RCAs and steel fibers were within a $12 \%$ error band. For the RCA beams with openings and steel fibers, the model by Shanmugam and Swaddiwudhipong [27] provided predicted-to-measured shear capacity ratio in the range of 0.97 to 1.17 whereas the ratio based on the model by Ray and Reddy [48] was in the range 0.71 to 0.98 .

Author Contributions: Conceptualization, T.E.-M., H.E.-H. and N.K.; methodology, T.E.-M., H.E.-H. and N.K.; validation, T.E.-M., H.E.-H. and N.K.; formal analysis, N.K. and T.E.-M.; investigation, N.K., T.E.-M. and H.E.-H.; resources, T.E.-M.; data curation, N.K.; writing-original draft preparation, N.K.; writing-review and editing, T.E.-M., H.E.-H., B.E.-A. and N.K.; visualization, N.K.; supervision, T.E.-M., H.E.-H. and B.E.-A.; project administration, T.E.-M.; funding acquisition, T.E.-M. All authors have read and agreed to the published version of the manuscript.

Funding: This research was funded by UAE University, grant number 12N004.

Data Availability Statement: The data presented in this study are available on request from the corresponding author. The data are not publicly available due to privacy issues.

Conflicts of Interest: The authors declare no conflict of interest.

\section{References}

1. Radonjanin, V.; Malešev, M.; Marinković, S.; Malty, A.E.S.A. Green recycled aggregate concrete. Constr. Build. Mater. 2013, 47, 1503-1511. [CrossRef]

2. Debieb, F.; Kenaï, S.; Courard, L.; Degeimbre, R. Mechanical and durability properties of concrete using contaminated recycled aggregates. Cem. Concr. Compos. 2010, 32, 421-426. [CrossRef]

3. Guo, M.; Grondin, F.; Loukili, A. Numerical analysis of the failure of recycled aggregate concrete by considering the random composition of old attached mortar. J. Build. Eng. 2020, 28, 101040. [CrossRef]

4. Wagih, A.; El-Karmoty, H.; Ebid, M.; Okba, S. Recycled construction and demolition concrete waste as aggregate for structural concrete. HBRC J. 2013, 9, 193-200. [CrossRef]

5. Rahal, K.N.; Alrefaei, Y.T. Shear strength of recycled aggregate concrete beams containing stirrups. Constr. Build. Mater. 2018, 191, 866-876. [CrossRef]

6. Wardeh, G.; Ghorbel, E. Shear strength of reinforced concrete beams with recycled aggregates. Adv. Struct. Eng. 2019, 22, 1938-1951. [CrossRef]

7. Al Mahmoud, F.; Boissiere, R.; Mercier, C.; Khelil, A. Shear behavior of reinforced concrete beams made from recycled coarse and fine aggregates. Structures 2020, 25, 660-669. [CrossRef]

8. Fathifazl, G.; Razaqpur, A.G.; Isgor, O.B.; Abbas, A.; Fournier, B.; Foo, S. Shear strength of reinforced recycled concrete beams without stirrups. Mag. Concr. Res. 2009, 61, 477-490. [CrossRef]

9. Khergamwala, P.C.; Singh, J.; Kumar, R. Experimental study on shear behavior of reinforced recycled aggregate concrete beams. Int. J. Civ. Eng. Technol. IJCIET 2016, 7, 128-139.

10. American Concrete Institute ACI. Building Code Requirements for Structural Concrete and Commentary on Building Code Requirements for Structural Concrete (ACI 318R-14); American Concrete Institute (ACI): Farmington Hills, MI, USA, 2014.

11. El-Maaddawy, T.; Sherif, S. FRP composites for shear strengthening of reinforced concrete deep beams with openings. J. Compos. Struct. 2009, 60, 197-204. [CrossRef]

12. Yang, K.H.; Eun, H.C.; Chung, H.S. The influence of web openings on the structural behavior of reinforced concrete high-strength concrete deep beams. Eng. Struct. 2006, 28, 1825-1834. [CrossRef]

13. Yang, K.H.; Ashour, A.F. Effectiveness of web reinforcement around openings in continuous concrete deep beams. ACI Struct. J. 2008, 105, 414-424.

14. Campione, G.; Minafo, G. Behaviour of concrete deep beams with openings and low shear span-to-depth ratio. Eng. Struct. 2012, 41, 294-306. [CrossRef]

15. Hu, O.E.; Tan, K.H.; Liu, X.H. Behaviour and strut-and-tie predictions of high strength concrete deep beams with trapezoidal web openings. Mag. Concr. Res. 2007, 59, 529-541. [CrossRef]

16. Aly, S.A.; Ibrahim, M.A.; Khttab, M.M. Shear behavior of reinforced concrete beams casted with recycled coarse aggregate. Eur. J. Adv. Eng. Technol. 2015, 2, 59-71.

17. Shi, C.; Li, Y.; Zhang, J.; Li, W.; Chong, L.; Xie, Z. Performance enhancement of recycled concrete aggregate-A review. J. Clean. Prod. 2016, 112, 466-472. [CrossRef] 
18. Gao, D.; Zhang, L.; Nokken, M. Mechanical behavior of recycled coarse aggregate concrete reinforced with steel fibers under direct shear. Cem. Concr. Compos. 2017, 79, 1-8. [CrossRef]

19. Kachouh, N.; El-Hassan, H.; El-Maaddawy, T. Effect of steel fibers on the performance of concrete made with recycled concrete aggregates and dune sand. Constr. Build. Mater. 2019, 213, 348-359. [CrossRef]

20. Kachouh, N.; El-Hassan, H.; El-Maaddawy, T. Influence of steel fibers on the flexural performance of concrete incorporating recycled concrete aggregates and dune sand. J. Sustain. Cem. Based Mater. 2021, 10, 165-192. [CrossRef]

21. Amin, A.; Foster, S.J. Shear strength of steel fibre reinforced concrete beams with stirrups. Eng. Struct. 2016, 111, 323-332. [CrossRef]

22. Cucchiara, C.; La Mendola, L.; Papia, M. Effectiveness of stirrups and steel fibres as shear reinforcement. Cem. Concr. Compos. 2004, 26, 777-786. [CrossRef]

23. Kang, T.H.K.; Kim, W.; Kwak, Y.K.; Hong, S.G. Shear testing of steel fiber-reinforced lightweight concrete beams without web reinforcement. ACI Struc. J. 2011, 108, 553-561.

24. Ma, K.; Qi, T.; Liu, H.; Wang, H. Shear behavior of hybrid fiber reinforced concrete deep beams. Materials 2018, 11, 2023. [CrossRef]

25. Kachouh, N.; El-Maaddawy, T.; El-Hassan, H.; El-Ariss, B. Shear Behavior of Steel-Fiber-Reinforced Recycled Aggregate Concrete Deep Beams. Buildings 2021, 11, 423. [CrossRef]

26. Mansur, M.; Alwist, W. Reinforced fibre concrete deep beams with web openings. Int. J. Cem. Compos. Lightweight Concr. 1984, 6, 263-271. [CrossRef]

27. Shanmugam, N.; Swaddiwudhipong, S. Strength of fibre reinforced concrete deep beams containing openings. Cem. Concr. Compos. 1988, 10, 53-60. [CrossRef]

28. Swaddiwudhipong, S.; Shanmugam, N.E. Fiber-reinforced concrete deep beams with openings. J. Struct. Eng. 1985, 111, 1679-1690. [CrossRef]

29. Al-Sarraf, S.; Al-Shaarbaf, I.A.S.; Diab, A.S. Effect of steel fiber on the behavior of deep beams with and without web opening. Eng. Technol. J. 2011, 29, 1-19.

30. Sahoo, D.R.; Flores, C.A.; Chao, S.H. Behavior of steel fiber-reinforced concrete deep beams with large opening. ACI Struct. J. 2012, 109, 193-204.

31. Oliveros, C. Designation: C33/C33M-16 Standard Specification for Concrete Aggregates 1. Available online: https://www.academia. edu/39073939/Designation_C33_C33M_16_Standard_Specification_for_Concrete_Aggregates_1 (accessed on 6 June 2021).

32. ASTM C09 Committee; Test Method for Soundness of Aggregates by Use of Sodium Sulfate or Magnesium Sulfate. ASTM International: West Conshohocken, PA, USA, 2013.

33. ACI Committee E-701. Cementitious Materials for Concrete; American Concrete Institute: Farmington Hills, MI, USA, 2013.

34. Hossain, M.S.; Lane, D.; Schmidt, B. Use of the Micro-Deval Test for Assessing the Durability of Virginia Aggregates. 2007. Available online: https://www.virginiadot.org/vtrc/main/online_reports/pdf/07-r29.pdf (accessed on 6 June 2021).

35. ASTM C131. Standard Test Method for Resistance to Degradation of Small-Size Coarse Aggregate by Abrasion and Impact in the Los Angeles Machine. Engineering360. Available online: https://standards.globalspec.com/std/842158/ASTM\%20C131 (accessed on 6 June 2021).

36. ASTM C09 Committee; Test Method for Relative Density (Specific Gravity) and Absorption of Coarse Aggregate. ASTM International: West Conshohocken, PA, USA, 2015.

37. Bekaert. Dramix 3D 65/35 Data Sheet. Bekaert, Belgium. Available online: https://www.bekaert.com/en/product-catalog/ content/dop/ \{\}//-/media/Files/ImportFiles/DRAMIX-3D/Dramix-3D-6535BG-6535BG.pdf?sc_lang=en-US (accessed on 4 January 2022).

38. El-Hassan, H.; Elkholy, S. Enhancing the performance of alkali-activated slag-fly ash blended concrete through hybrid steel fiber reinforcement. Constr. Build. Mater. 2021, 311, 125313. [CrossRef]

39. ACI Committee 211.1-91. Standard Practice for Selecting Proportions for Normal, Heavyweight and Mass Concrete; American Concrete Institute: Farmington Hills, MI, USA, 2009.

40. ASTM C143; Standard Test Method for Slump of Hydraulic-Cement Concrete. ASTM International: West Conshohocken, PA, USA, 2015.

41. British Standard; Testing Hardened Concrete-Compressive Strength of Test Specimens, BS EN 12390-3. British Standard: London, UK, 2009.

42. ASTM C39; Standard Test Method for Compressive Strength of Cylindrical Concrete Specimens. ASTM International: West Conshohocken, PA, USA, 2015

43. ASTM C469; Standard Test Method for Static Modulus of Elasticity and Poisson's Ratio of Concrete in Compression. ASTM International: West Conshohocken, PA, USA, 2014.

44. ASTM C496/C496M-17; Standard Test Method for Splitting Tensile Strength of Cylindrical Concrete Specimens. ASTM International: West Conshohocken, PA, USA, 2017.

45. Cos, A.; Heghes, B.; Negrutiu, C.; Kiss, Z. Strain and displacement measurements in reinforced self-compacting concrete beams with openings using digital image correlation technique. Proceedings 2021, 63, 39. [CrossRef]

46. Funari, M.F.; Verre, S. The effectiveness of the dic as a measurement system in SRG shear strengthened reinforced concrete beams. Crystals 2021, 11, 265. [CrossRef]

47. Kong, F.K.; Sharp, G.R. Structural idealization for deep beams with openings. Mag. Concr. Res. 1977, 29, 81-91. [CrossRef] 
48. Ray, S.P.; Reddy, C.S. Strength of reinforced concrete deep beams with and without opening is the web. Indian Concr. J. 1979, 54, 242-246.

49. Alzard, M.H.; El-Hassan, H.; El-Maaddawy, T. Environmental and Economic Life Cycle Assessment of Recycled Aggregates Concrete in the United Arab Emirates. Sustainability 2021, 13, 10348. [CrossRef]

50. Braga, A.M.; Silvestre, J.D.; de Brito, J. Compared environmental and economic impact from cradle to gate of concrete with natural and recycled coarse aggregates. J. Clean. Prod. 2017, 162, 529-543. [CrossRef]

51. BREG. Environmental Product Declaration; BREG EN EPD No. 000065; Saint-Gobain Isover: Runcorn, UK, 2015.

52. Polat, G.; Arditi, D.; Ballard, G.; Mungen, U. Economics of on-site vs. off-site fabrication of rebar. Constr. Manag. Econ. 2006, 24, 1185-1198. [CrossRef]

53. Madar Emirates for Buildings Materials. Available online: https:/ /www.madar.com (accessed on 4 January 2022).

54. Sinopro Industrial Products. Available online: https:/ / sinopro.ae (accessed on 4 January 2022).

55. ACI Committee 544.6R. Report on Design and Construction of Steel Fiber-Reinforced Concrete Elevated Slabs; American Concrete Institute: Farmington Hills, MI, USA, 2015.

56. Senaratne, S.; Gerace, D.; Mirza, O.; Tam, V.W.Y.; Kang, W.H. The costs and benefits of combining recycled aggregate with steel fibres as a sustainable, structural material. J. Clean. Prod. 2016, 112, 2318-2327. [CrossRef]

57. Awchat, G.D.; Kumthekar, M.B. Cost-benefit analysis of using recycled coarse aggregate in plain and fibre reinforced concrete. Adv. Sci. Technol. Res. J. 2021, 15, 233-242. [CrossRef]

58. Tam, V.W.Y.; Mirza, O.; Senaratne, S.; Kang, W.H.; Kotrayothar, D. Shrinkage development of recycled aggregate concrete and future directions of using steel fibers as a reliable and cost-effective option. In Proceedings of the 38th Australasian Universities Building Education Association Conference 2013, Auckland, New Zealand, 20-22 November 2013. 